US Army Corps of Engineers ${ }_{\circledast}$

Engineer Research and

Development Center

\title{
FRDQ
}

Ecosystem Management and Restoration Research Program

\section{Draft Standard Monitoring Protocols for Herbaceous Vegetation}

Brook D. Herman

June 2019

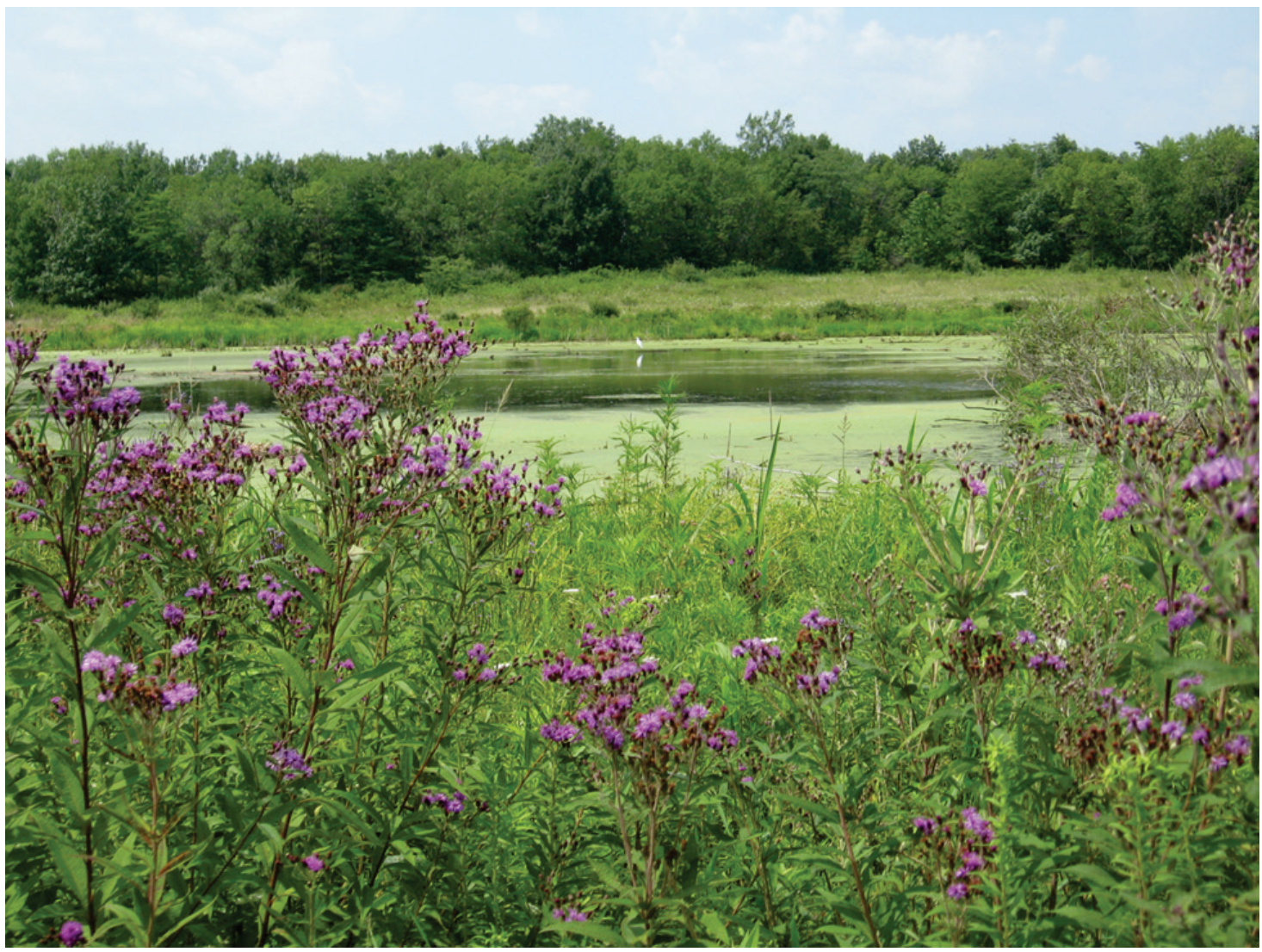


The US Army Engineer Research and Development Center (ERDC) solves the nation's toughest engineering and environmental challenges. ERDC develops innovative solutions in civil and military engineering, geospatial sciences, water resources, and environmental sciences for the Army, the Department of Defense, civilian agencies, and our nation's public good. Find out more at www.erdc.usace.army.mil.

To search for other technical reports published by ERDC, visit the ERDC online library at http://acwc.sdp.sirsi.net/client/default. 


\title{
Draft Standard Monitoring Protocols for Herbaceous Vegetation
}

\author{
Brook D. Herman \\ Environmental Laboratory \\ U.S. Army Engineer Research and Development Center \\ 3909 Halls Ferry Road \\ Vicksburg, MS 39180-6199
}

Final report

Approved for public release; distribution is unlimited
Prepared for U.S. Army Corps of Engineers
Washington, DC 20314-1000
Under Project 2015-ER-13, "Standard Monitoring Protocols for Herbaceous Vegetation"




\section{Abstract}

Many methods have been developed over the last century for measuring the characteristics or attributes of plant communities, however, there are no widely accepted standard methods for monitoring vegetation, especially for ecosystem restoration projects. This report presents the draft standard herbaceous vegetation monitoring protocols developed for the U.S. Army Corps of Engineers (USACE) for use in their Aquatic Ecosystem Restoration projects. The objectives of the protocols are the following: (1) to be able to detect changes in species composition and abundance between years at the same site, (2) to be comparable between sites, (3) to be effective in multiple habitat types, with an herbaceous vegetation layer, and regions of the continental United States, (4) to minimize personal or sampling biases, and (5) to be able to use data for the calculation of appropriate success metrics (e.g., diversity, condition, etc.). The protocols will be tested in the field at multiple restoration sites throughout the U.S. Final protocols will be refined or modified based on results of testing and will be made available to the public.

DISCLAIMER: The contents of this report are not to be used for advertising, publication, or promotional purposes. Citation of trade names does not constitute an official endorsement or approval of the use of such commercial products. All product names and trademarks cited are the property of their respective owners. The findings of this report are not to be construed as an official Department of the Army position unless so designated by other authorized documents. 


\section{Contents}

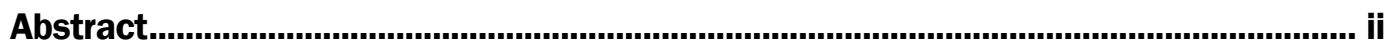

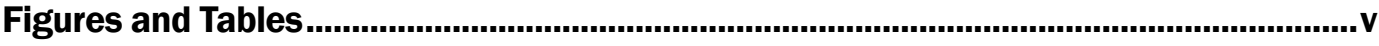

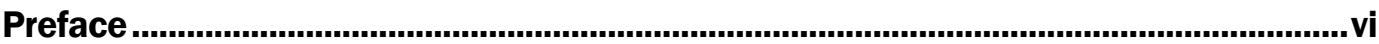

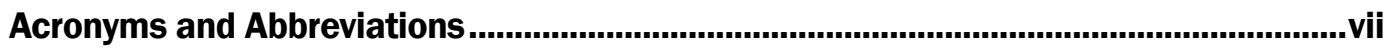

Unit Conversion Factors.....................................................................................................vifi

1 Introduction ...................................................................................................... 1

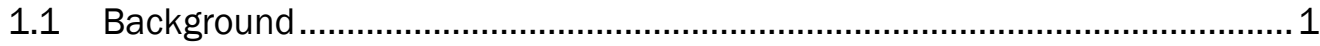

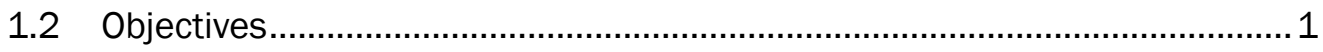

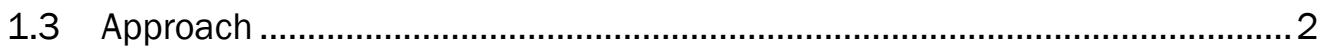

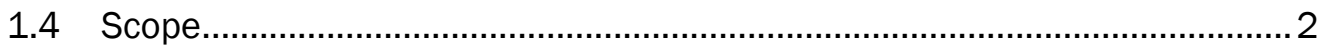

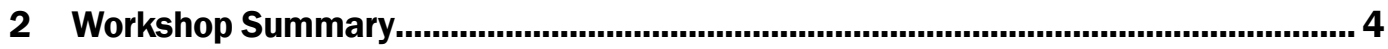

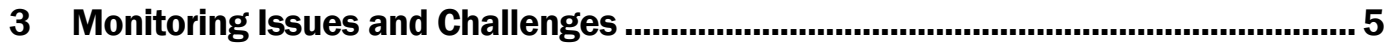

3.1 Quantitative vs. qualitative .................................................................... 5

3.2 Selecting an area to be sampled during monitoring .................................... 5

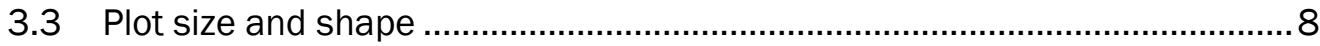

3.4 Placement of plots and transects............................................................

3.5 Type of data recorded from plot............................................................ 14

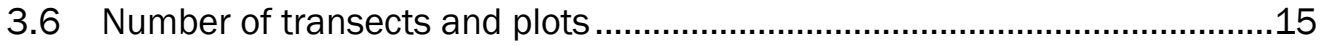

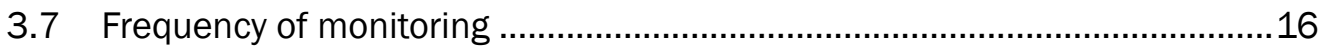

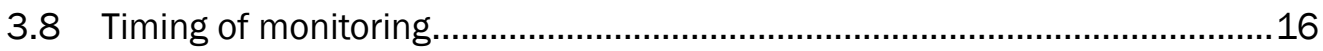

4 Draft Standard Herbaceous Monitoring Protocols ..................................................17

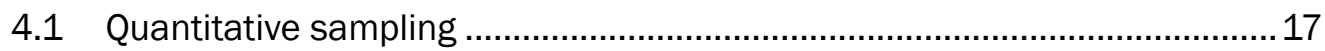

4.1.1 Selecting management units to be monitored ................................................ 17

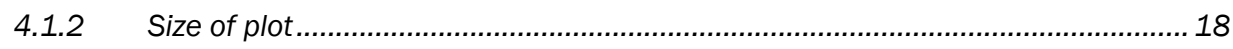

4.1.3 Placement of transects and plots ................................................................ 18

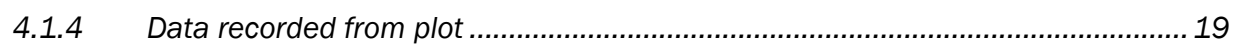

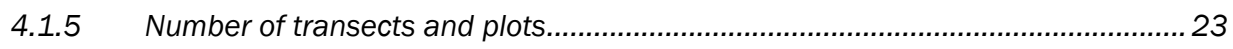

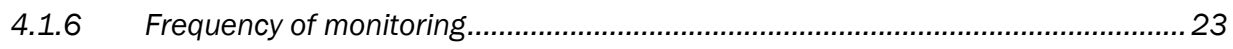

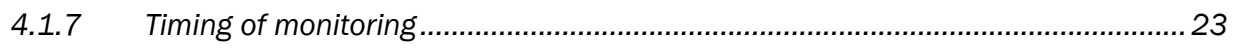

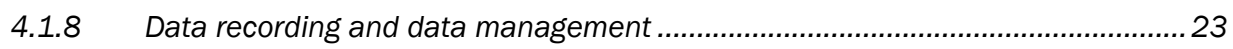

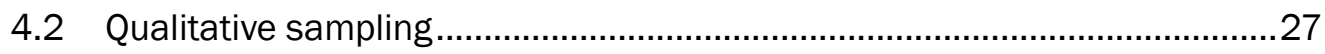

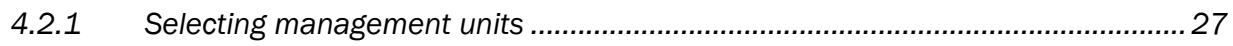

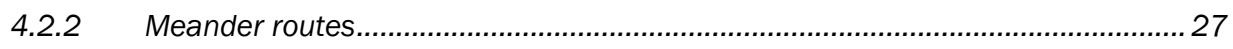

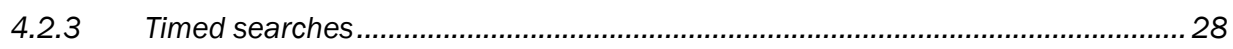

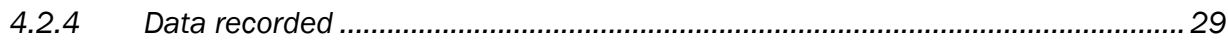

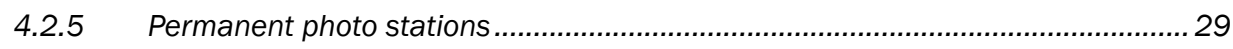


4.2.6 Frequency of timed searches .......................................................................... 30

4.2.7 Seasonality of timed searches ......................................................................... 30

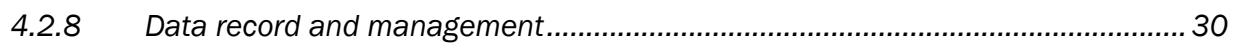

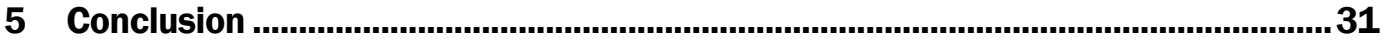

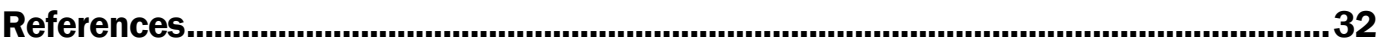

Report Documentation Page 


\section{Figures and Tables}

\section{Figures}

Figure 1. Photo of restoration site that includes multiple habitat types.............................. 7

Figure 2. Example of vegetation mapping for restoration site example............................... 8

Figure 3. Plot size and shape. $3 \mathrm{~A}$ has two plots of $0.25 \mathrm{~m}^{2}$ with the above plot missing one side for use in tall dense vegetation. 3B is also $0.25 \mathrm{~m}^{2}$ and has detachable sides that can be broken down and easily carried ........................................ 9

Figure 4. Nested plot - 0.25-m² plot within 1-m² plot...................................................... 10

Figure 5. Examples of plot and transect placement. $5 \mathrm{~A}$ is an example of a large continuous management unit that is able to accommodate long linear transects. Figure 5B is an example of small patches of a management unit that will accommodate short linear or non-linear transects. Figure $5 \mathrm{C}$ is an example of a long narrow management unit that requires the transect to be nonlinear. .......................13

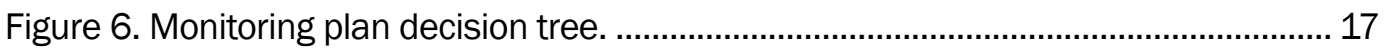

Figure 7. Example of plot of placement along a transect. ...................................................... 19

Figure 8. Example of percent cover estimation. *............................................................ 21

Figure 9. United States Geological Survey (USGS) percent cover estimation (USGS

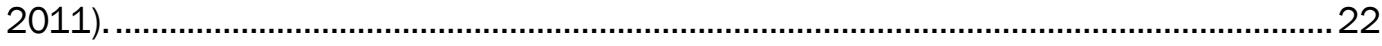

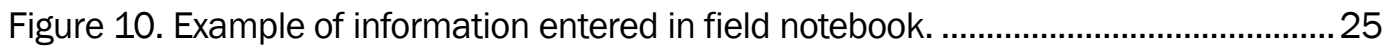

Figure 11. Examples of how to photograph unknown plants............................................26

\section{Tables}

Table 1. Summary of placement methods.................................................................... 12

Table 2. Information to be listed per transect............................................................... 24 


\section{Preface}

This study was conducted for the Ecosystem Management and Restoration Research Program (EMRRP) under Project 2015-ER-13, "Standard Monitoring Protocols for Herbaceous Vegetation."

The work was performed by the Wetlands and Coastal Ecology Branch (EEW) of the Ecosystem Evaluation and Engineering Division (EE), U.S. Army Engineer Research and Development Center, Environmental Laboratory (ERDC-EL). At the time of publication, Ms. Patricia M. Tolley was Chief, CEERD-EEW, Mr. Mark D. Farr was Chief, CEERD-EE, and Dr. Al Cofrancesco, CEERD-EZT, was the Technical Director for the EMRRP. The Deputy Director of ERDC-EL was Dr. Jack E. Davis and the Director was Dr. Ilker R. Adiguzel.

COL Ivan P. Beckman was the Commander of ERDC, and Dr. David W. Pittman was the Director. 


\section{Acronyms and Abbreviations}

\begin{tabular}{|l|l|}
\hline Term & Meaning \\
\hline DoD & Department of Defense \\
\hline EE & Ecosystem Evaluation and Engineering Division \\
\hline EEW & Wetlands and Coastal Ecology Branch \\
\hline EL & Environmental Laboratory \\
\hline EMRRP & $\begin{array}{l}\text { Ecosystem Management and Restoration Research } \\
\text { Program }\end{array}$ \\
\hline ERDC & $\begin{array}{l}\text { U.S. Army Corps of Engineers, Engineer Research and } \\
\text { Development Center }\end{array}$ \\
\hline GPS & Global Positioning Satellite \\
\hline USACE & U.S. Army Corps of Engineers \\
\hline USGS & United States Geological Survey \\
\hline VCWG & Vegetation Classification Working Group \\
\hline
\end{tabular}




\section{Unit Conversion Factors}

\begin{tabular}{|l|c|l|}
\hline Multiply & \multicolumn{1}{l|}{ By } & To Obtain \\
\hline acres & $4,046.873$ & square meters \\
\hline cubic feet & 0.02831685 & cubic meters \\
\hline cubic inches & $1.6387064 \mathrm{E}-05$ & cubic meters \\
\hline cubic yards & 0.7645549 & cubic meters \\
\hline feet & 0.3048 & meters \\
\hline hectares & $1.0 \mathrm{E}+04$ & square meters \\
\hline inches & 0.0254 & meters \\
\hline miles (nautical) & 1,852 & meters \\
\hline miles (US statute) & $1,609.347$ & meters \\
\hline square feet & 0.09290304 & square meters \\
\hline square inches & $6.4516 \mathrm{E}-04$ & square meters \\
\hline square miles & $2.589998 \mathrm{E}+06$ & square meters \\
\hline square yards & 0.8361274 & square meters \\
\hline yards & 0.9144 & meters \\
\hline
\end{tabular}




\section{Introduction}

\subsection{Background}

Numerous methods have been developed over the last century for measuring the characteristics or attributes of plant communities (Bonham 2013), however, there are no widely accepted standard methods for monitoring vegetation. The results of most methods that have been developed are not readily comparable (Bonham 2013). Additionally, although there are numerous institutions, agencies, and programs focused on sampling and monitoring vegetation, there is little publicly available guidance on how to design effective, unbiased, repeatable vegetation data collection protocols (Bonham 2010; Wildi 2013; Albert et al. 2010). Thus, there is a need to develop standard monitoring protocols for vegetation that will allow comparability between sites, between years at the same site, and is effective at detecting changes in species composition and abundance to inform management decisions.

\subsection{Objectives}

The purpose of this report is to present the process that was used to develop a draft (beta) version of standard herbaceous vegetation monitoring protocols for use by the U.S. Army Corps of Engineers (USACE). The following objectives of the protocols are:

- to be able to detect changes in species composition and abundance between years at the same site,

- to be comparable between sites,

- to be effective in various habitat types, with an herbaceous vegetation layer present, and applicable in multiple regions of the continental United States,

- to minimize personal or sampling biases, and

- to be able to use data for the calculation of appropriate success metrics (e.g., diversity, condition, etc.).

These protocols are being developed for the USACE for their use during the monitoring phase of their ecosystem restoration projects. Currently, the USACE has no standards in place for ecosystem restoration monitoring, including vegetation. Standardization of vegetation 
monitoring protocols will allow tracking the response of vegetation relative to restoration actions over many sites. This will maximize the understanding of how certain restoration techniques achieve specific restoration goals. In addition, tracking vegetation response in such a robust way will help the USACE to identify and refine effective restoration techniques and potentially decrease construction costs. Most importantly, these data will be used to calculate success metrics. Communicating the success and benefits of ecosystem restoration in a manner that is easily interpreted (i.e., simple numerical indices), is key to garnering public and vertical chain support for ecosystem restoration.

\subsection{Approach}

Monitoring the change in ecosystems as a result of restoration actions over time is a key component in the adaptive management of a restoration project. Making informed management decisions requires that monitoring data be collected in a manner that will answer the management questions (i.e., are invasive species invading), and be effective so as to not miss a critical change or falsely detect a change that would trigger an unwarranted management decision. Monitors cannot reasonably sample each individual plant within an area of concern, therefore, data collection protocols must be designed to collect enough subsamples of the plant community to detect the majority of plant species present and reasonably estimate their relative abundance. Developing standard protocols can be challenging when considering potential complexities and amount of ground to be evaluated within area of concern (e.g., species area relationship, changes in hydrology within area, etc.) and constrained by budget and time.

\subsection{Scope}

The draft standard monitoring protocols for herbaceous vegetation are being developed for use in areas that have a significant layer of herbaceous vegetation (i.e., grasslands, tidal marshes, riparian areas, and oak savannas). The protocols would not be appropriate to sample nonherbaceous dominated vegetation layers (e.g., shrub or tree layers). The protocols are being specifically developed for use during the monitoring and adaptive management phases of a project, post construction, or after initial restoration activities. Additionally, these would also be suitable for pre-restoration, to establish baseline conditions, and during construction and initial restoration activities. Also, these protocols are being developed 
to detect changes in plant communities in their entirety, and not necessarily in one specific species. Additional species specific monitoring protocols may be needed if there are threatened and endangered plant species that are part of the restoration project (Elzinga et al. 1998). Last, these protocols are expected to be used in conjunction with other monitoring activities for tracking changes in other aspects of the ecosystem, such as other biotic components (e.g., fish, birds, etc.) or functions (e.g., nutrient uptake, hydrology, etc.). 


\section{Workshop Summary}

A one-day workshop, "Standard Monitoring Protocols for Herbaceous Vegetation," was held on 4 April 2017, in Vicksburg, MS. USACE personnel from five districts and divisions, academics from four universities, and researchers from the USACE-Environmental Laboratory (EL) participated in the workshop. The goals of the workshop were to cultivate a better understanding of the type of monitoring protocols being used today, and to come to consensus on forming the basic foundation of a nation-wide standard herbaceous vegetation monitoring protocol.

The workshop started with presentations from the participants that covered a range of vegetation monitoring projects, including monitoring restoration and mitigation projects, research projects, and long-term ambient monitoring (e.g., tracking condition of ecosystem without restoration or management). Common topics covered in the presentations included: placement of sampling transects and/or plots, type of data recorded from each plot or transect, how often sampling occurred, and size and shape of sample plot. Once presentations were concluded, the workshop participants worked through each of the foundational issues that formed the basis of a testable version of the standard protocols.

One theme that emerged from the various presentations was that there is a wide variety of protocols that are being used. No two projects presented used the same protocol. The size and shape of the sample plots ranged from 0.25 meters $(\mathrm{m}) 2$ to $4.57-\mathrm{m}(15$ feet $(\mathrm{ft})$ ) circular radius to line point intercept. The type of data recorded also varied between projects. Most projects identified individual plant species found in a sample plot to species level, although some recorded plants according to their growth form alone, such as grass, forb, shrub, etc. Placement of transects and/or plots ranged from systematic, to stratified, to random. At the conclusion of the presentations, it was apparent that there was no single overarching method to monitor vegetation and that the various protocols represented differences in monitoring goals and objectives, skill set, and budget. Nevertheless, participants agreed that a standardized protocol would be necessary in order to make comparisons among sites or report data at a region-al or national level. 


\section{Monitoring Issues and Challenges}

Once presentations were concluded, the participants were led through a list of topics related to herbaceous vegetation monitoring protocols that need to be addressed for the formulation of a set of standards. The following are the list of topics discussed, a summary of their importance and conclusions of the workshop participants.

\subsection{Quantitative vs. qualitative}

For the purposes of this report, quantitative sampling refers to the methods that record multiple sample plots, qualitative sampling refers to methods that do not use multiple sample plots for recording species richness and relative abundance. It is much more difficult to ensure a standard set of information was collected with a standard unit of effort with qualitative sampling, making it difficult to ensure appropriate comparability between years and between sites. However, qualitative sampling can be much faster and less costly to execute than quantitative sampling. For this reason, workshop participants concluded that the standard protocols must include both types of sampling, with a high degree of necessity placed on quantitative sampling. If at all possible, monitoring herbaceous vegetation should include a basic level of quantitative sampling in order to ensure appropriate comparability and to ensure that success metrics can be calculated and communicated with certain degree of confidence.

Furthermore, the qualitative protocols also must have set standards, such as amount of time an area is searched, or amount of area searched and visually assessed, how to establish fixed photo points, and what kind of data should always be reported with such methods.

\subsection{Selecting an area to be sampled during monitoring}

The goal of standardized vegetation monitoring is to collect data from a predetermined area in a consistent manner in order to detect changes to that area over time. Generally, restoration projects are not one homogenous unit of vegetation or habitat. Restoration projects are typically heterogeneous sites driven by differences in abiotic (e.g., geomorphology, topology, and hydrology) and biotic factors (e.g., beavers, sea lions, etc.). Restoration sites are usually a complex array of different vegetation types or communities that support different ecological functions and different suites or guilds of species (e.g., grass seed eaters, 
aquatic plant herbivores, etc.) (Figure 1). Different vegetation or habitat types usually require different management regimes or techniques to either enhance certain aspects or control specific types of invasive species. Workshop participants concluded that delineating separable management units is necessary to minimize variation when trying to detect changes in species composition and relative abundance over time. Identifying specific vegetation types and management units is typically determined during the planning phases of a project and restoration goals and objectives are then formulated around these vegetation types (Figure 2). However, even the best laid plans cannot account for variation in yearly climatic conditions and actual conditions on the site during construction. Thus, changes in vegetation types and management units may occur during the design and construction of a project. The goal would be to then ensure new management units are included in the monitoring plan of the restoration project. An example of identifying management units, and hence sampling units, is a tidal marsh restoration that includes low and high marsh. Low and high marsh are delineated by differences in elevation and depth at which they are inundated during high tide. Both low and high marsh areas would be considered management units, and therefore, separate areas of concern for monitoring purposes. 
Figure 1. Photo of restoration site that includes multiple habitat types.

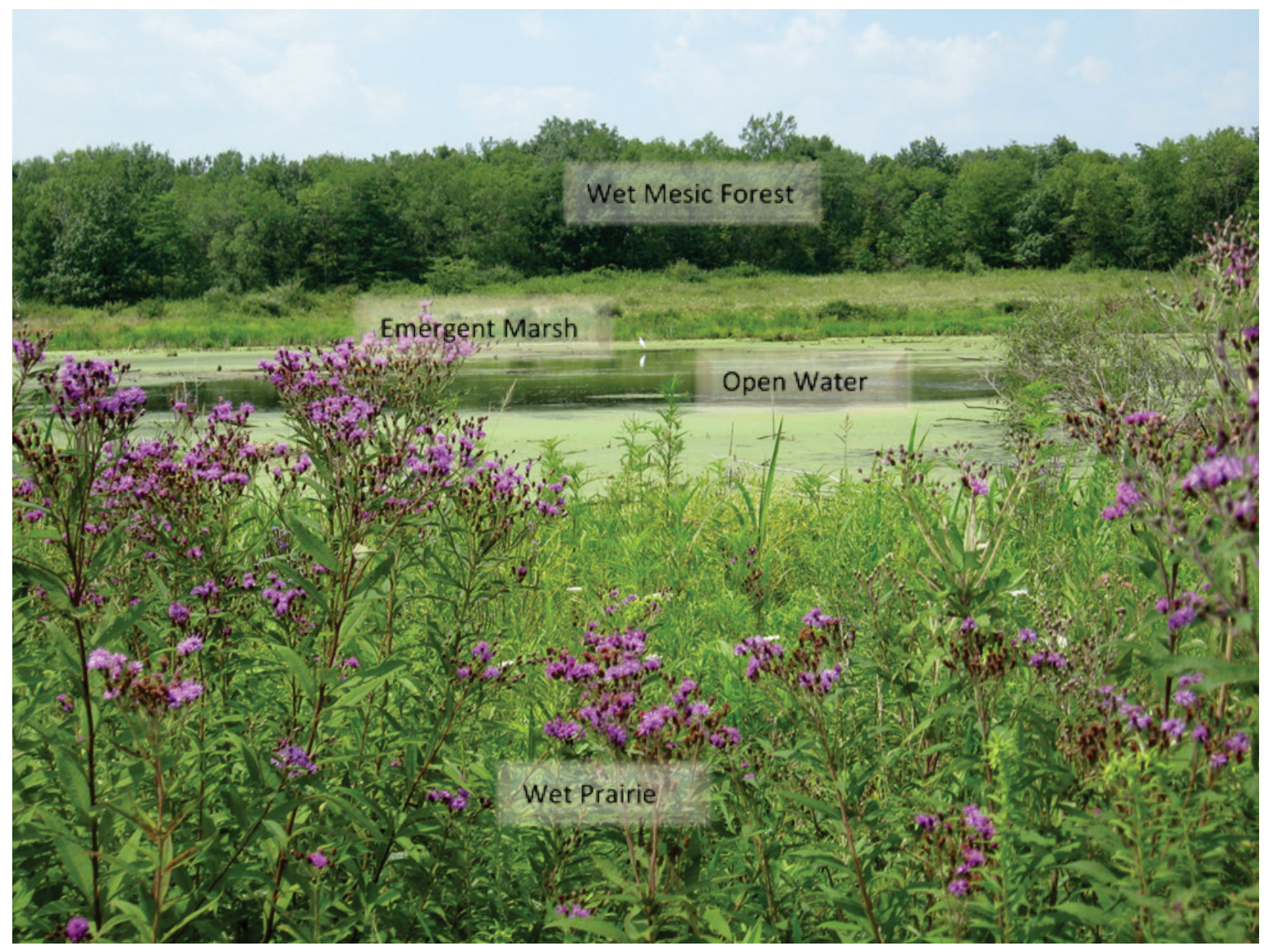


Figure 2. Example of vegetation mapping for restoration site example.

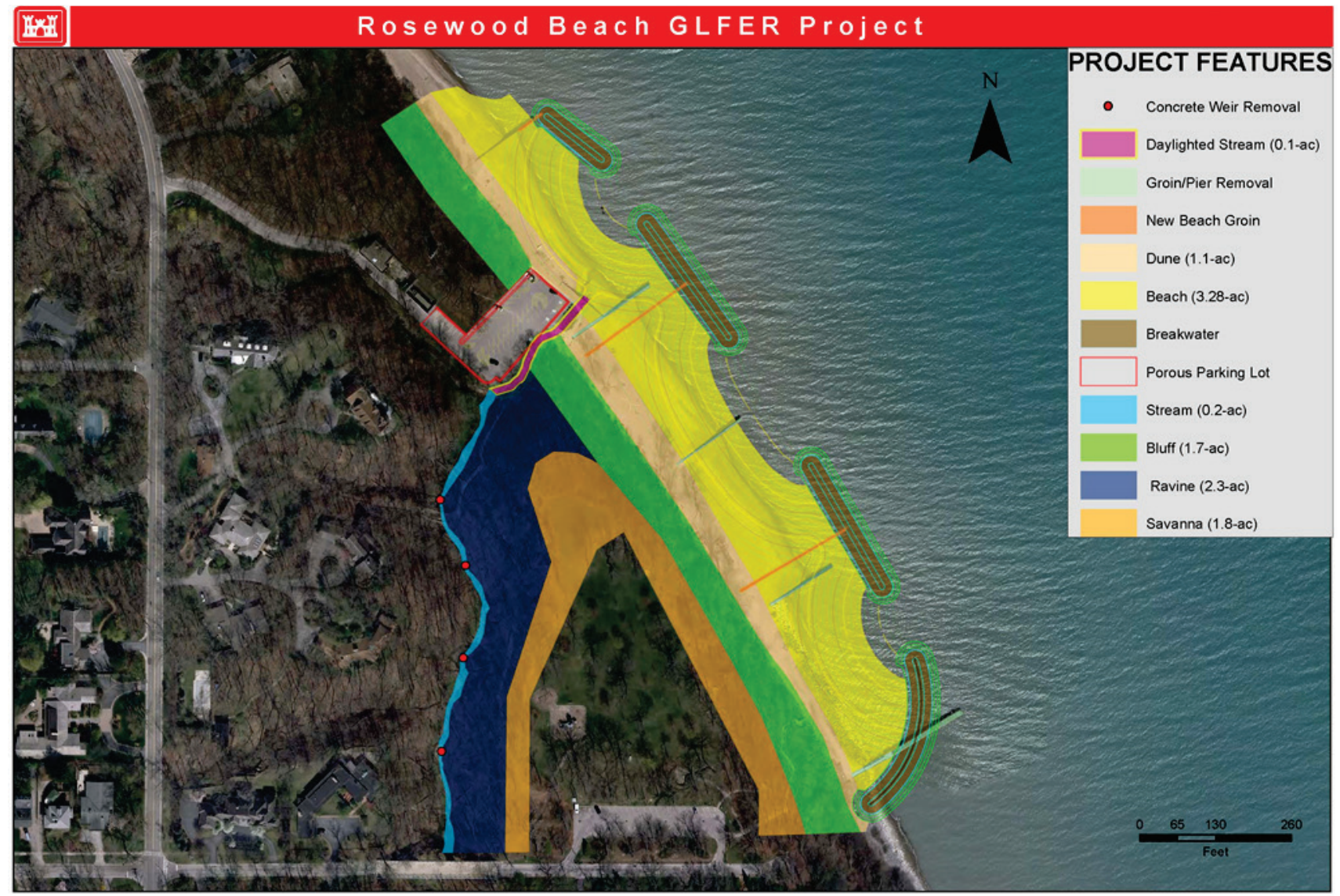

\subsection{Plot size and shape}

A plot is a pre-determined unit of area that is one sample of an entire plant community of concern. A plant community is defined as a vegetation stand or type that is relatively homogeneous in terms of structure, species composition, and environment, so that variation is minimized within and maximized between plots (VCWG 2018; Dengler et al. 2009) Typically, there are numerous plots sampled within an area of concern (plant community). Plots can also be referred to as quadrats if they are square in shape. A plot can be almost any shape or size, as depicted by the presentations during the workshop. Workshop participants discussed various pros and cons of using different sized and shaped plots. For a more thorough treatment of differences in plot size and species detection/estimation, please consult Otýpková and Chytrý (2006), Kenkel and Podani (1991), and Gotelli and Colwell (2001). The group decided that a square shape should be standard and that in all but one vegetation type, the plot should be $0.25 \mathrm{~m}^{2}$ (Figure 3). This decision was based on the ability of monitors to efficiently move through an area of concern (e.g., bigger sizes 
are unwieldy and may slow down monitors moving through tall vegetation) and quickly record all species that occur within the plot (e.g., the bigger the plot, the more area has to be assessed). Additionally, the plot is appropriate at detecting individual species, such that the plot is large enough to encompass multiple individual plants, and estimate their relative abundance. Workshop participants had experience working with multiple sized and shaped plots. Last, even though the smaller plot did not cover as much ground in one sample, sampling more of the smaller plots at a faster rate was just as effective at detecting species and their relative abundance.

Figure 3. Plot size and shape. $3 \mathrm{~A}$ has two plots of $0.25 \mathrm{~m}^{2}$ with the above plot missing one side for use in tall dense vegetation. $3 B$ is also $0.25 \mathrm{~m}^{2}$ and has detachable sides that can be broken down and easily carried
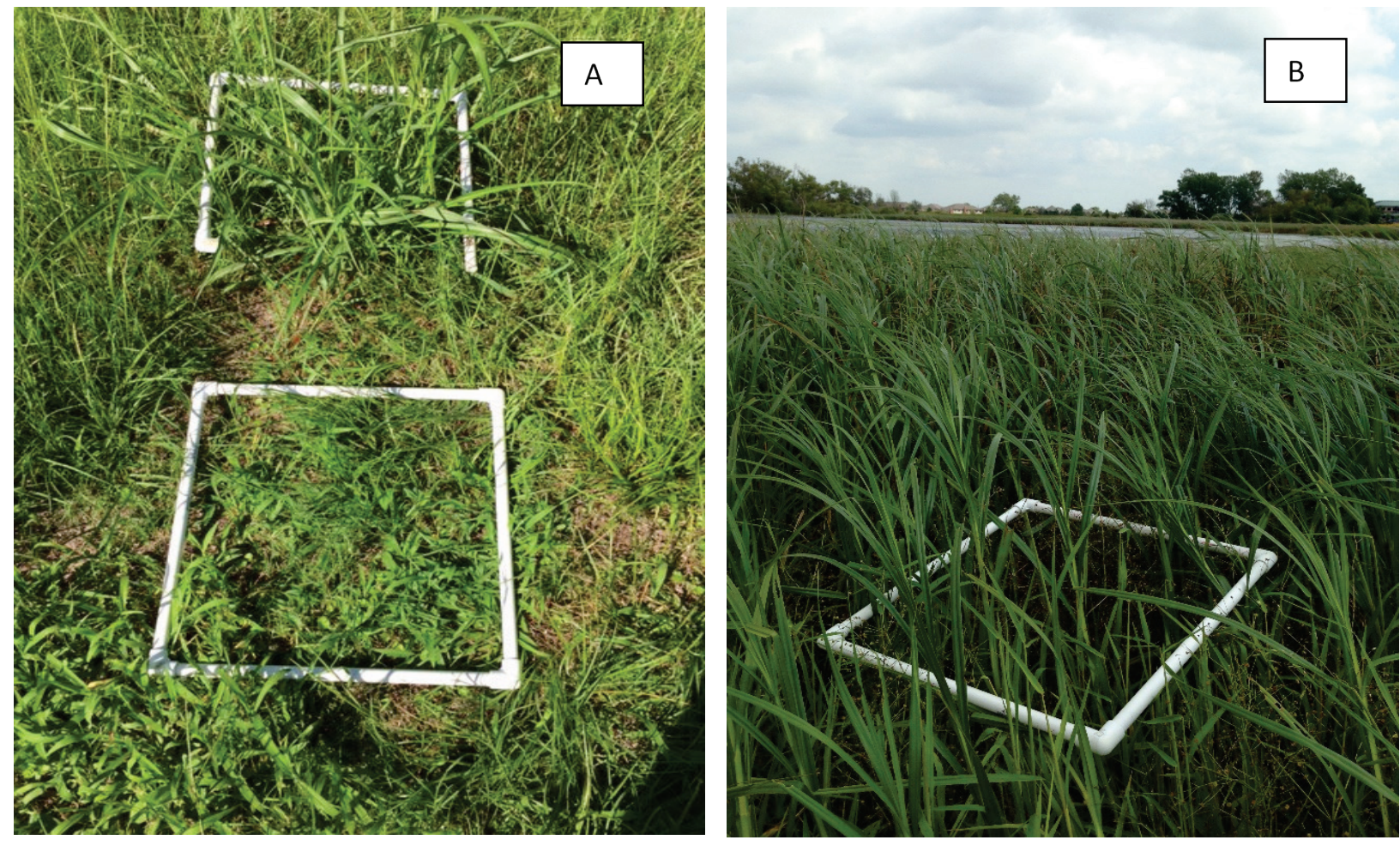

Figure $3 \mathrm{~A}$ has two plots of $0.25 \mathrm{~m}^{2}$ with the above plot missing one side for use in tall dense vegetation. Figure $3 \mathrm{~B}$ is also $0.25 \mathrm{~m}^{2}$ and has detachable sides that can be broken down and easily carried.

The workshop participants recognized that although the smaller plot was appropriate for vegetation that is evenly dispersed throughout an area (e.g., Figure $3 \mathrm{~B}$ ), sparsely distributed vegetation in an area will require a larger plot in order to ensure that at least one individual plant is likely to occur within a sampled plot. Therefore, the workshop participants 
recommended a $1 \mathrm{~m}^{2}$ plot, with the $0.25 \mathrm{~m}^{2}$ plot nested within the $1 \mathrm{~m}^{2}$, be used for sparsely vegetated areas (Figure 4). Examples of sparsely vegetated types include coastal sand dunes, arid/desert regions, and closed canopy forest herbaceous layer. The reason for the nested plots is consistency with the standard unit of measurement, which is the $0.25 \mathrm{~m}^{2}$ plot, and ability to appropriately compare overall vegetation recovery patterns between sites. Nested plots are have been researched and recommended from past studies (Stohlgren et al. 1995).

Figure 4. Nested plot $-0.25-\mathrm{m}^{2}$ plot within $1-\mathrm{m}^{2}$ plot.

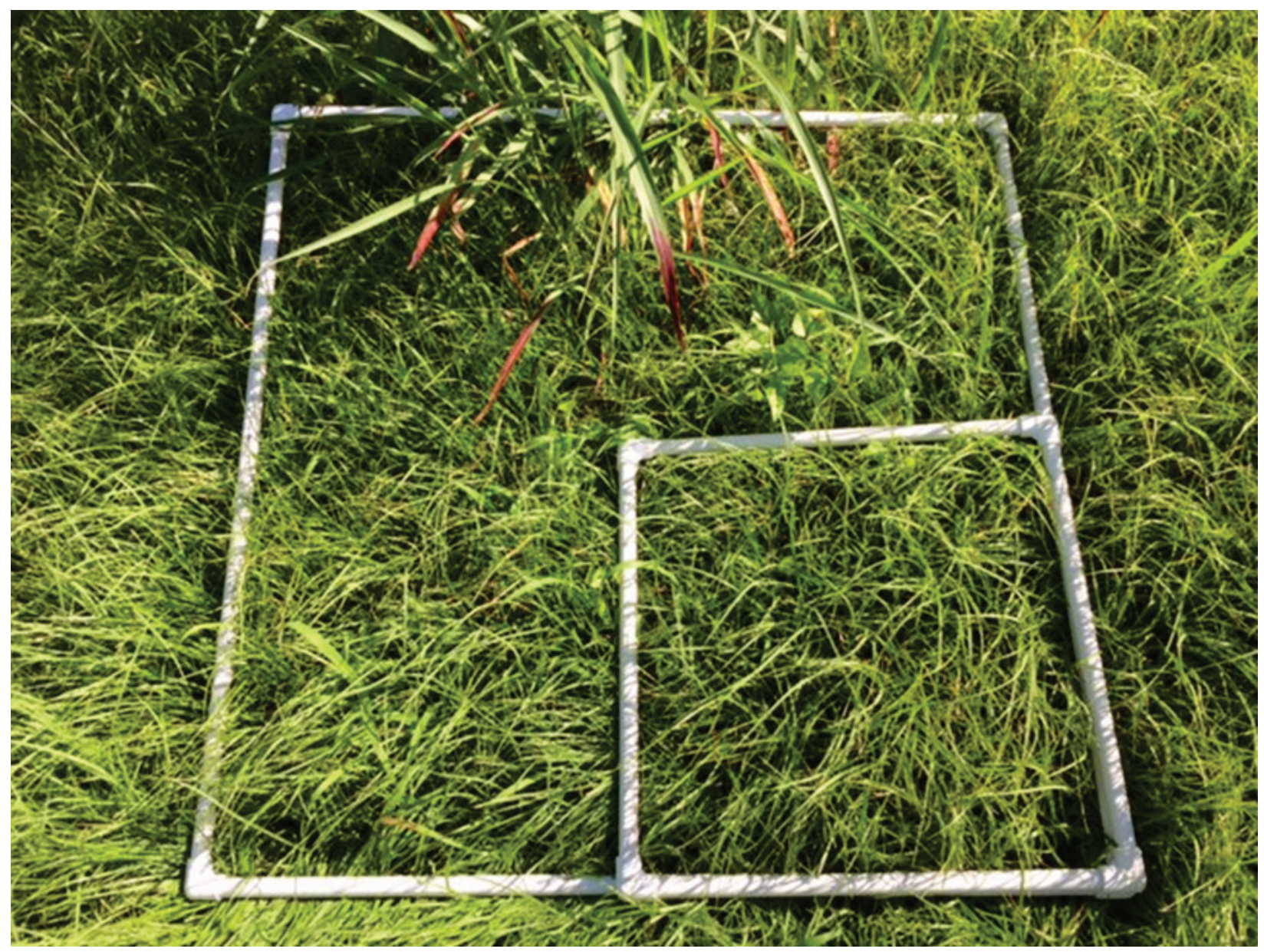

\subsection{Placement of plots and transects}

Once the areas to be sampled have been delineated, placement of plots and transects must then be decided. Placement could be completely random within the management unit. The drawback of this method is the amount of time it takes to execute, including time required to overlay an appropriate grid size over a map of the area, using a random numbers table to select a number of grid cells to be sampled, and finding all of the 
randomly selected grid cells in the field. The least time consuming method is to start placing plots in the area of concern that is the easiest to access and then placing a predetermined number of plots along a route that is easiest to navigate. However, the data collected is likely to be biased because of the subjective haphazard method used to collect the samples, such that they are neither random nor independent. Biased data could indicate conditions that are not representative of the site as a whole, resulting in faulty management decisions. The goal of a standard protocol is to develop a cost efficient placement procedure that minimizes potential bias, while still being effective at detection and estimation of species relative abundance.

Repeatedly sampling plots in an exact location along a permanently placed transect, referred to as permanent plots, can provide improved accuracy within the plots sampled, reduce potential non-informative variation (i.e., differences over time that may be due to different areas sampled between years and not a change in vegetation), and eliminate sampling subjectivity. A potential drawback of this method is that changes occurring outside of the plots (e.g., new invader), would not be recorded from the plot based samples. This may make it hard to justify or enforce certain management decisions if changes are not recorded through quantitative sampling. Additionally, permanent plots may encourage selective management in terms of treating the area with the plots separately from the rest of the management unit. Finally, excessive trampling is a risk if the plots are sampled every year and/or sampled more than once per year.

A method that is somewhere between completely random and haphazard is the stratified semi-random plot transect sampling design, achieved with mixed random and permanent plot placement. Stratified semi-random requires the sample area to represent a particular type of habitat or population, and then the samples are taken to represent certain characteristics of the area of concern (e.g., environmental gradient, bird use of area, etc.) (Jensen and Bourgeron 2001). Basically, stratified semirandom allows data collection to occur that supports the assumption of random independence, minimizes bias and potential subjectivity, while allowing a priori selection of sample area. (Parker et al. 2011).

Stratified semi-random plot transect sampling requires selecting the starting point of data collection, or beginning of transect, in a location that is representative of the area of concern. The starting point should not be 
too close to the edge, or ecotone, and should also allow enough space for the number of pre-determined plots to be sampled between the start and end of transect. Plots are then placed a certain distance from one another along the transect. There are a number of ways to further randomize the placement of plots along the transect while in the field. The level of randomization depends on how the data are to be scrutinized by other interested parties or used in certain statistical analyses. Transects may be any length that is necessary to capture the spacing required between plots and may be any shape that will accommodate the shape of the management unit. Figure 5 shows examples of different shaped management units and placement of transects.

In conclusion, the placement of plots and transects should meet the needs of the management question for the area of concern with a level of accuracy and precision for the least investment in time and cost.

Determining appropriate level of accuracy and precision should take place during the planning phase of a project. Determinations may be made through pilot studies using a variety of plot and transect placement techniques or through a review of literature and reports that are representative of the type of vegetation under restoration/management and that face similar management challenges (e.g., invasive species). Table 1 is a brief summary of the pros and cons of each placement technique.

Table 1. Summary of placement methods.

\begin{tabular}{|l|l|l|}
\hline Method & Pros & Cons \\
\hline Permanent & $\begin{array}{l}\text { Easier to repeat between years and } \\
\text { between observers. Reduced } \\
\text { variation between years. }\end{array}$ & $\begin{array}{l}\text { May not detect change occurring in } \\
\text { greater area. May encourage } \\
\text { differential management. }\end{array}$ \\
\hline Random & $\begin{array}{l}\text { Discourages differential } \\
\text { management. Decreased } \\
\text { subjectivity. Meets statistical } \\
\text { assumptions. }\end{array}$ & $\begin{array}{l}\text { Less precise between years than } \\
\text { permanent. Allows more variation } \\
\text { between years. May take more time } \\
\text { to execute. }\end{array}$ \\
\hline $\begin{array}{l}\text { Stratified Semi- } \\
\text { Random }\end{array}$ & $\begin{array}{l}\text { May detect change in community } \\
\text { early on. Discourages differential } \\
\text { management. }\end{array}$ & $\begin{array}{l}\text { Less precise between years than } \\
\text { permanent. Allows more variation } \\
\text { between years. More efficient than } \\
\text { random to execute. }\end{array}$ \\
\hline
\end{tabular}


Figure 5. Examples of plot and transect placement. 5A is an example of a large continuous management unit that is able to accommodate long linear transects. Figure $5 \mathrm{~B}$ is an example of small patches of a management unit that will accommodate short linear or non-linear transects. Figure $5 \mathrm{C}$ is an example of a long narrow management unit that requires the transect to be nonlinear.

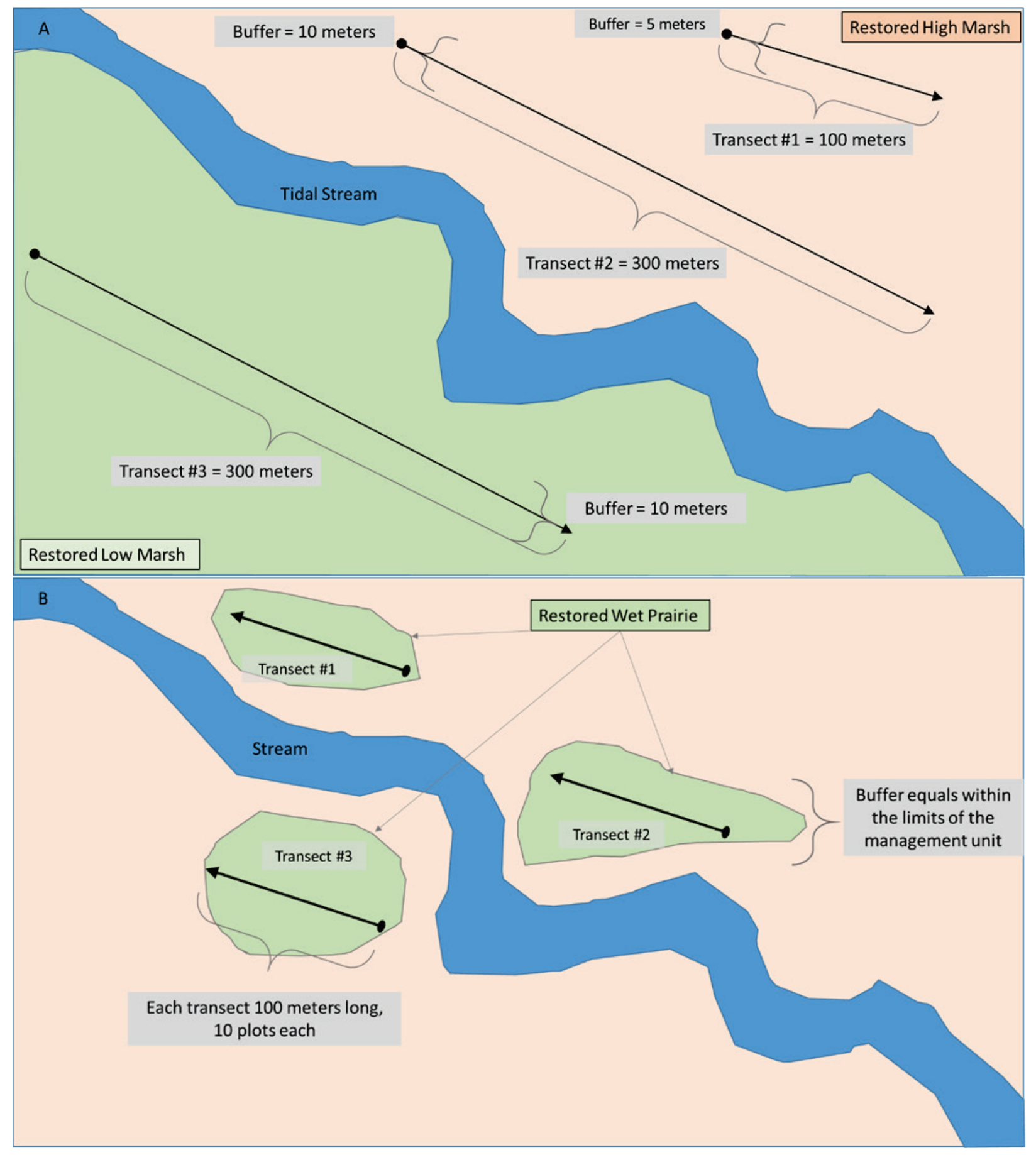




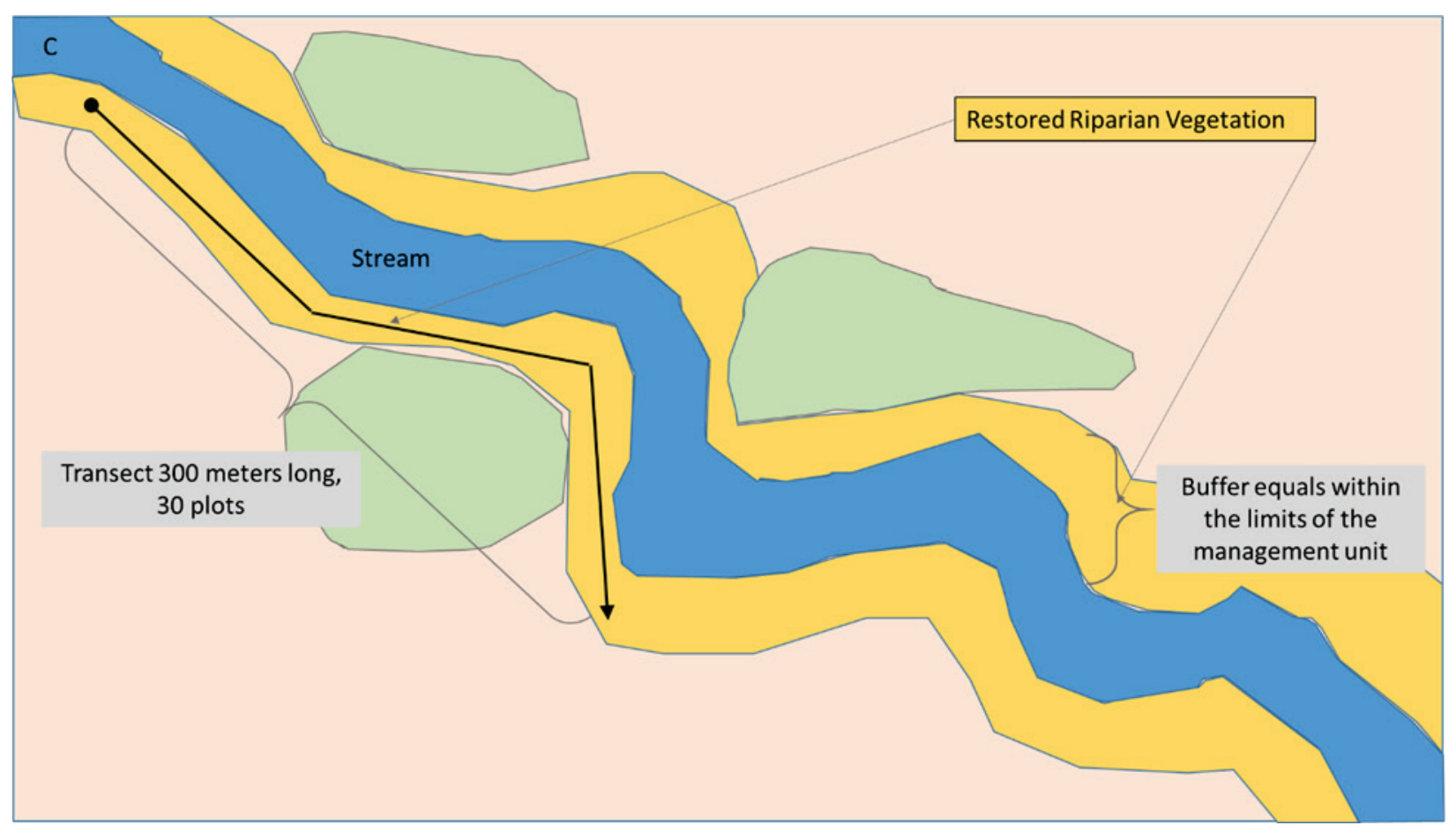

All examples are not to scale. Please note that 'buffer' refers to the width, on either side, along the transect a plot may be placed. Figure $5 \mathrm{~A}$ is an example of a large continuous management unit that is able to accommodate long linear transects. Figure $5^{\mathrm{B}}$ is an example of small patches of a management unit that will accommodate short linear or nonlinear transects. Figure $5 \mathrm{C}$ is an example of a long narrow management unit that requires the transect to be nonlinear.

\subsection{Type of data recorded from plot}

All individual plants should be identified to species level, if possible, and their associated percent cover in $5 \%$ increments (starting with $1 \%$, then $5 \%, 10 \%$, etc.) should be recorded from each plot. Although it is much faster to record presence of species without percent cover, detecting certain thresholds or triggers for specific management techniques may require a more robust understanding of the relative abundance of specific species. In addition, relative frequency of plant species and/or a list of plant species present can be distilled from this type of data, if needed.

Percent cover increments of $5 \%$ were chosen over the use of cover classes (categories), such as Daubenmire, because cover classes usually group increments into large ranges of cover (e.g., $5-25 \%, 25-50 \%$, etc.) that may be too rough to effectively inform management decisions. More time may 
be required to estimate cover for each species using $5 \%$ increments, as compared to assigning a cover value and as with any visual estimate training observers to identify cover in the same way is paramount to minimizing bias.

The presence of an individual plant that is unidentifiable down to species level should still be recorded from the plot. Recording all species, regardless of level of taxonomic identification, is important for the calculation of many success metrics, such as species richness and diversity. If able, and appropriate to do so (e.g., not a threatened and endangered species), one or two individual plants may be taken from the site for further investigation. Care of individual plant specimens will be described in later sections.

All plant species, either rooted or overhanging the plot, including woody stems less than $1 \mathrm{~m}$ tall and less than 8 centimeters $(\mathrm{cm})$ (3 in.) diameter at breast height (1.37 $\mathrm{m}$ above the ground), must be recorded from the plot. Woody plant stems taller than $1 \mathrm{~m}$ and $8 \mathrm{~cm}$ (3 in.) or greater diameter at breast height are considered part of the shrub or tree layer and are not be considered part of the herbaceous layer (Environmental Laboratory 1987).

\subsection{Number of transects and plots}

In general, the more area that is sampled, the more accurate the estimates of species richness and relative abundance (Palmer 1990). The number of plots placed along transects is an important determinant of how well the plant community is characterized with the monitoring protocols. For vegetation types that exhibit even dispersion of species (e.g., low tidal marsh), fewer plots will be needed to detect the majority of species and to estimate their relative abundance. Relative abundance refers to how much area is covered per species in relation to other species. However, vegetation that is unevenly dispersed (aggregated random dispersion) (e.g., arid/desert) would require more plots to effectively sample. A minimum number of ten plots per transect, and at least one transect per management unit, is recommended. However, that relatively small number of plots would not be sufficient for many vegetation types (e.g., wet meadow) that have two or three dominant species along with many more uncommon, randomly dispersed species. At least 30 plots per management unit is the recommended baseline information. For very large management areas over approximately 40 ha (100 acres), and with 
an appropriate budget, as many transects and plots should be sampled as necessary to confidently answer management questions.

\subsection{Frequency of monitoring}

During the early stages of native plant restoration, plant communities can undergo radical changes in species composition and relative abundance and should be monitored on a regular basis. At least one sampling period per year during restoration activities, and within the first five years after initial restoration activities have ceased, are recommended sampling intervals. After the first five years after restoration activities, then sampling can be reduced to once every three to five years.

\subsection{Timing of monitoring}

Monitoring of herbaceous vegetation is best performed during the growing season, when the plant community is at maximum maturity without the loss of too many early bloomers or exclusion of later bloomers. Monitoring during the growing season may be best completed during a time that management units are most easily accessed (e.g., floodwaters have receded), and when species identifying characteristics are maximized (e.g., flowers, seed formation, etc.). For most of North America, this occurs from July October. However, early spring blooming species may not be detectable at that time period. If spring or early summer blooming species (e.g., Carex) are an important management concern, it is recommended that spring monitoring occur along with another monitoring event later in the season. 


\section{Draft Standard Herbaceous Monitoring Protocols}

The following is a description of the beta version of the standard monitoring protocols for herbaceous vegetation. The protocols were formulated to be executed in a wide variety of vegetation types and are flexible enough to be appropriate for projects that have different management challenges and budgetary constraints. Figure 6 is a helpful layout of the decisions that need to be made prior to conducting monitoring protocols.

Figure 6. Monitoring plan decision tree.

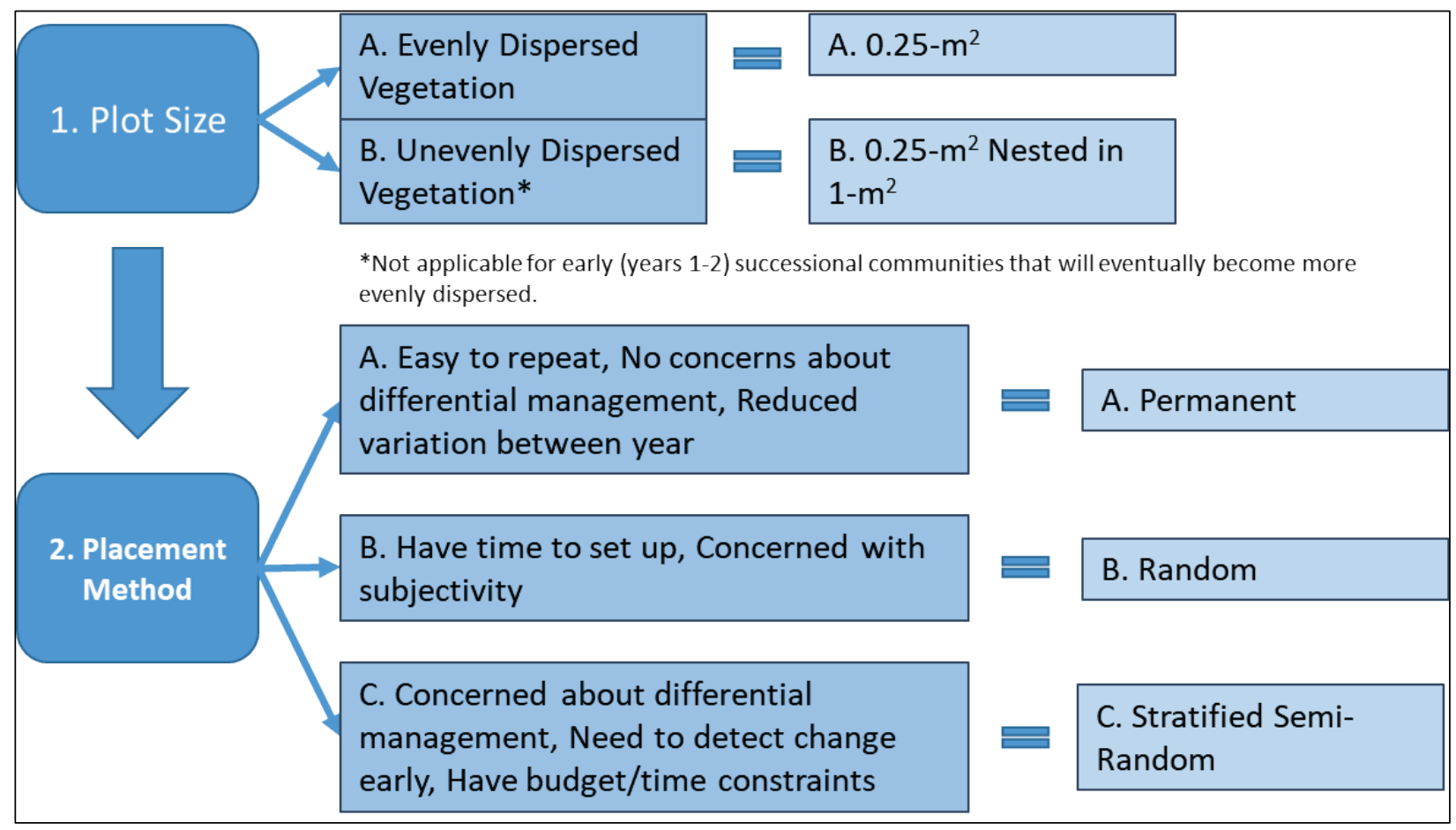

\subsection{Quantitative sampling}

\subsubsection{Selecting management units to be monitored}

First, vegetation types (e.g., low vs. high marsh) should be mapped and identified. Each vegetation type that is a part of the restoration project should be treated as a management unit that may have separate management concerns. The following sections are related to the way each of the management units should be monitored through the life of the construction, monitoring, and adaptive management phases. 


\subsubsection{Size of plot}

A $0.25 \mathrm{~m}^{2}$ plot must be the size used to monitor most vegetation types. For vegetation types that are sparse and randomly dispersed, a $1 \mathrm{~m}^{2} \mathrm{plot}$, with a $0.25 \mathrm{~m}^{2}$ plot nested within the $1 \mathrm{~m}^{2}$, is recommended.

\subsubsection{Placement of transects and plots}

Locate the start and end of each transect a random distance, between $5-$ 20 meters, from the edge of the management unit in a manner that would allow enough space to accommodate the pre-determined number of plots to be sampled. At least one transect must be sampled per management unit. At least 30 total plots must be sampled from each management unit. Plots may be broken out into multiple transects, depending on the size and shape of the management unit (Figure $5^{\mathrm{B}}$ ). The location of the start and end of every transect must be mapped (Global Positioning Satellite (GPS) coordinates, described with nearby landmarks, etc.) and relocated for future monitoring events.

Plots must be placed within a buffer zone that is at least five meters wide, but no more than ten meters, running parallel with transect. Buffers from different transects must not overlap. First, determine the length of the each transect. Then, determine the number of plots (minimum of ten) that will be placed along this transect. Divide the transect length by the number of plots to determine the plot spacing, D. The rules of how the plots will be placed along the transect will be determined based on field conditions (e.g., Figure 5), potential scrutiny of data, and how the data will be analyzed. One method is to begin by placing the bottom corner of the first plot even with the zero mark along the center line of transect, the second plot will be placed at distance $\mathrm{D}$, the third plot will be placed at $2 \mathrm{D}$, the fourth at $3 \mathrm{D}$, and so on until the last plot. A recommended method that includes semi-randomness is if each plot is placed a random distance from the transect line, within the five - ten meter buffer. Also, the direction of placement from the transect center line may also be alternating or random. If needed, consult a random numbers table or generate a random numbers list to determine a distance within the buffer and/or a direction from the transect center line. See Figure 6 for an example of plot placement.

An important aspect of this step is to thoroughly describe the rules that were used to place the plots along the transect in a monitoring plan or report. This is to ensure that the same plot placement rules are applied for 
each monitoring event, thus, increasing the comparability between years and decreasing the potential for sampling bias.

Figure 7 uses a fixed distance between plots (D). Plots are placed alternating left/right from center line of transect. The distance between the plot and the center line of is a random distance between one and five meters as dictated by the buffer (note: increase randomization by randomly placing either left or right). The list of random numbers should be consulted or generated, and printed out prior to field visit. Figure 7 is not to scale.

Figure 7. Example of plot of placement along a transect.

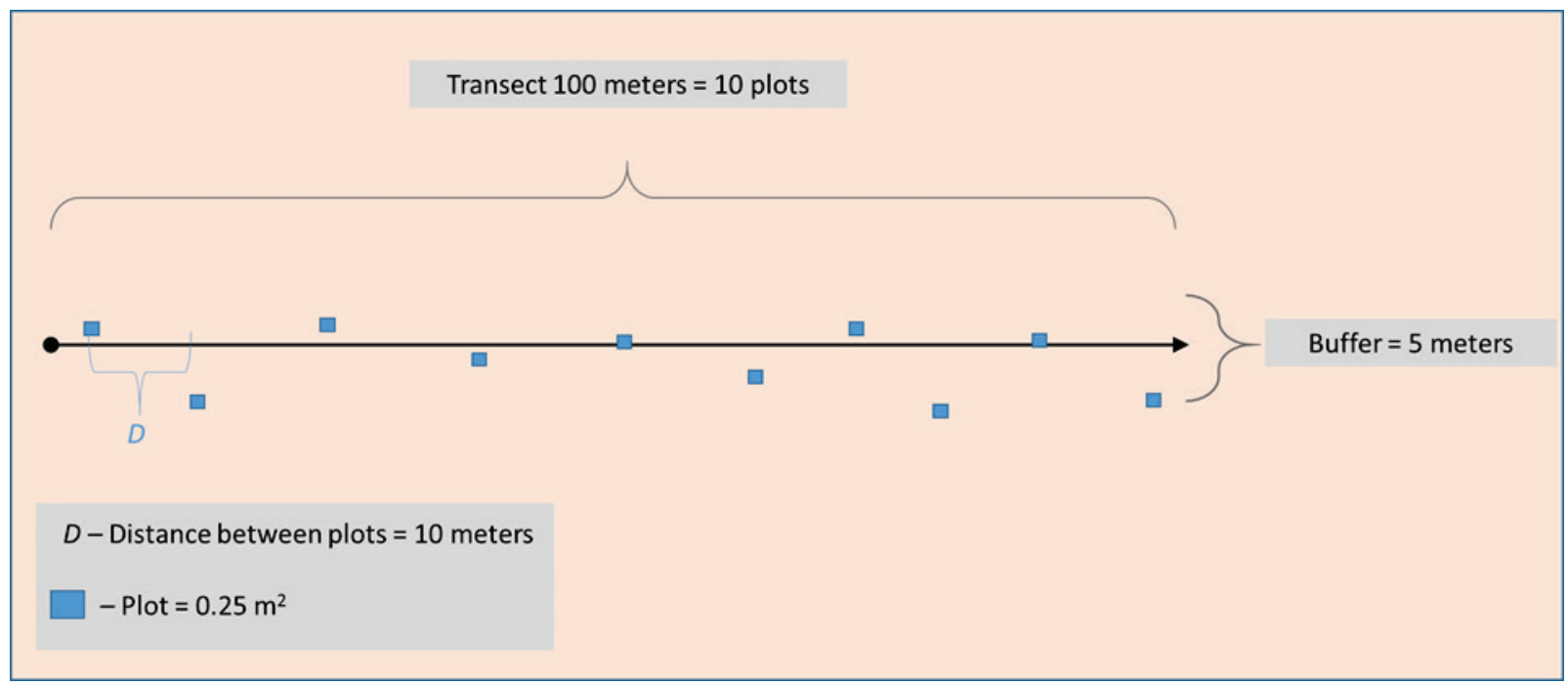

\subsubsection{Data recorded from plot}

All species, rooted or overhanging, found within the plot must be recorded along with their associated percent cover. Percent cover must be recorded starting with $1 \%$, then increase the coverage in $5 \%$ increments (e.g., $5 \%$, $10 \%, 15 \%$, etc.), up to $100 \%$ for any one species. Overlapping foliage of the same species is not considered separately in cover estimates, but overlapping foliage by different species is considered separately. Thus, some plots may total more than $100 \%$ coverage because there may be overlapping among species. An example of how to assess coverage is if an individual species is identified as a small single stem, that species would be recorded with a percent cover of $1 \%$ (Figures 8 and 9). Woody stems less than $1 \mathrm{~m}$ tall and less than $8 \mathrm{~cm}$ (3 in.) diameter at breast height (1.37 $\mathrm{m}$ above the ground) must be recorded from the plot. Woody plant stems taller than $1 \mathrm{~m}$, and $8 \mathrm{~cm}$ (3 in.) or greater in diameter at breast height, are 
considered part of the shrub or tree layer, not part of the herbaceous layer, and would require a separate protocol to effectively monitor. 
Figure 8. Example of percent cover estimation.*

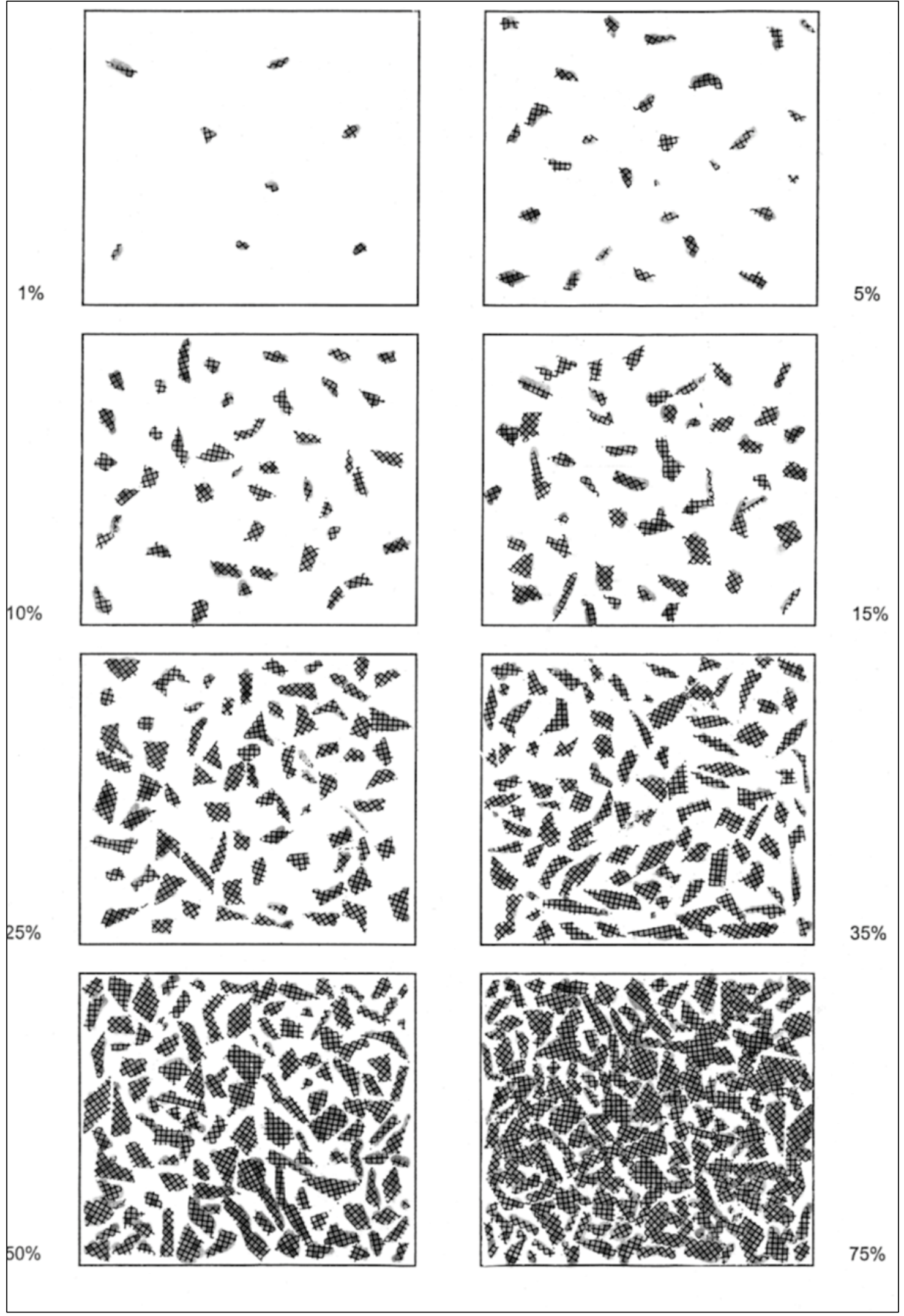

*(http://www.cnps.org/cnps/vegetation/pdf/percent cover diag-cnps.pdf). 
Figure 9. United States Geological Survey (USGS) percent cover estimation (USGS 2011).

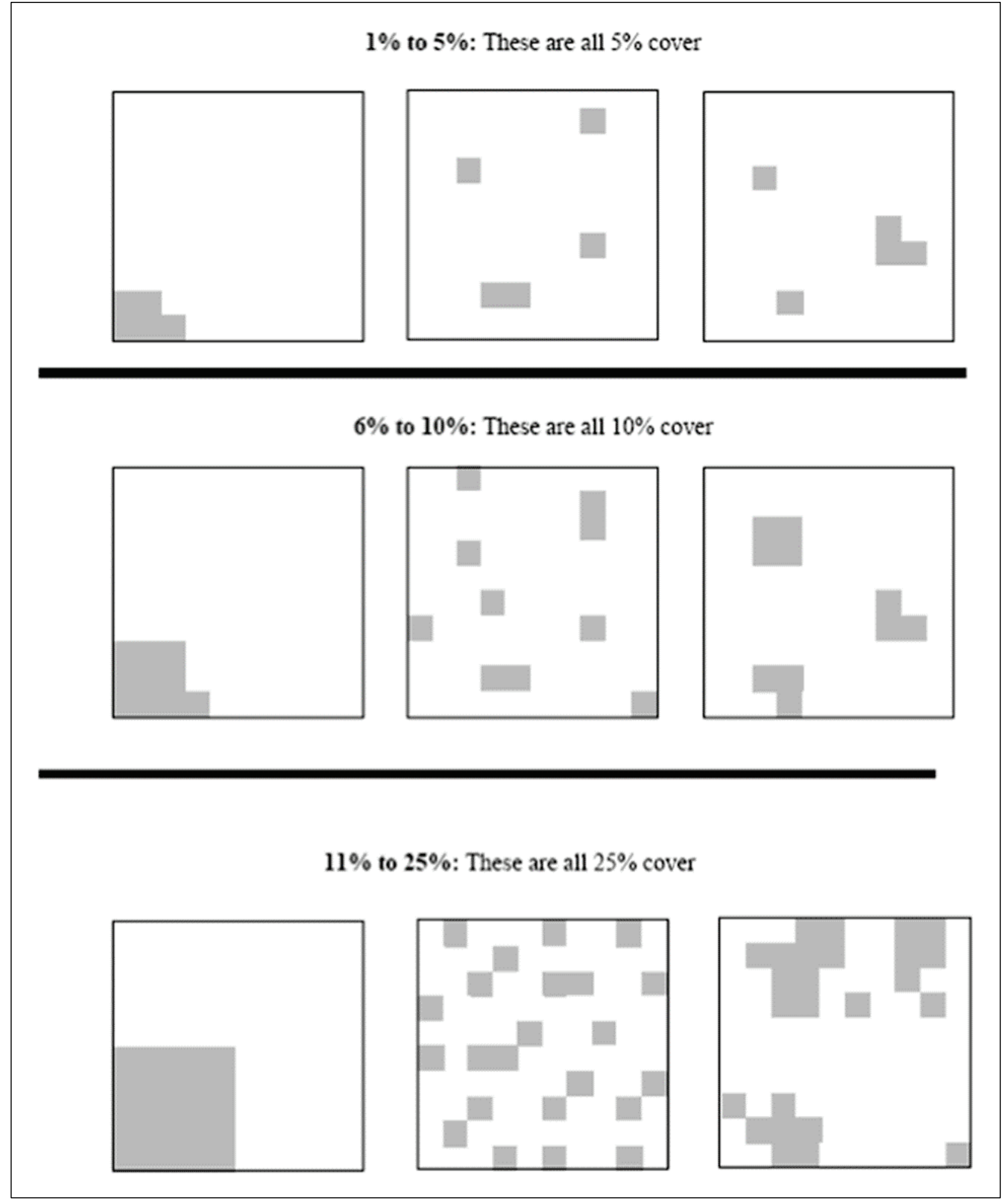




\subsubsection{Number of transects and plots}

At a minimum, 30 plots must be sampled from each management unit. Plots may be parsed out along one or multiple transects. At a minimum, ten plots should be sampled from each transect. Fewer than ten plots per transect may not justify the extra effort to locate and sample an additional transect. Additional plots and transects may be sampled to meet the needs of the management questions.

\subsubsection{Frequency of monitoring}

Sites should be monitored a minimum of one sampling period per year during restoration activities, and within the first five years after initial restoration activities have ceased. After the first five years after restoration activities, then sampling can be reduced to once every three to five years.

\subsubsection{Timing of monitoring}

Monitoring should occur during the growing season during a time that is easiest to access management units (e.g., after floodwaters recede) and maximizes species identifying characteristics (e.g., flowers, seed formation, etc.). This occurs from July-October. Spring blooming species may not be detectable at that time. If spring or early summer blooming species (e.g., Carex) are an important management concern, it is recommended that spring monitoring occur along with another monitoring event later in the season.

\subsubsection{Data recording and data management}

Recording data in the field requires appropriate field data sheets or notebooks. It is recommended to use paper that can be used during wet conditions (e.g., Rite in the Rain). Data sheets can be prepared ahead of time, but are not necessary. What is necessary is that the data recorded be easily interpreted by current or future monitors. Correct interpretation is increased when recording the full scientific name of each species, however, this is time consuming. The use of species acronyms, a combination of letters unique to each species, is much faster to write in the field. The use of species acronyms is only appropriate if all current and future monitors have the ability to correctly reference the acronyms with their scientific name. Many regional floras have agreed upon species acronyms (e.g., Flora of Chicago Region). If the region to be monitored does not have a set of recognized acronyms, it is encouraged that monitors develop a list of 
species known from the area and assign unique acronyms to each species. Once the list is complete, it must be shared among all monitors and placed in an accessible location, (i.e., District website, separate folder on a shared drive, paper copies in safe place, etc.). Table 2 lists information that should be included on each data sheet or notebook page for each transect. Figure 10 is an example of a field notebook that was used to record plot based vegetation data that did not use of pre-prepared data sheet.

Table 2. Information to be listed per transect.

\begin{tabular}{|l|l|}
\hline Information & Notes \\
\hline Date & day, month, year \\
\hline Name(s) of Monitor & $\begin{array}{l}\text { Even though it may be your notebook, and you will know } \\
\text { who recorded the data, the person that takes over for you } \\
\text { once you leave or retire from the position may need to } \\
\text { know this information. }\end{array}$ \\
\hline Site & Project name. \\
\hline Management Unit or Locale & $\begin{array}{l}\text { Specific type of vegetation or unique management unit } \\
\text { name. }\end{array}$ \\
\hline Transect Number and Description & $\begin{array}{l}\text { Unique name or label of transect, start location of the } \\
\text { transect (GPS coordinates), how far the start is from the } \\
\text { edge of management unit, compass bearing/direction } \\
\text { toward end, length of transect, location of end (GPS } \\
\text { coordinates), rules of plot placement, etc. }\end{array}$ \\
\hline No. of Plots & \begin{tabular}{l} 
Expected number of plots to be sampled from transect. \\
\hline
\end{tabular}
\end{tabular}


Figure 10. Example of information entered in field notebook.

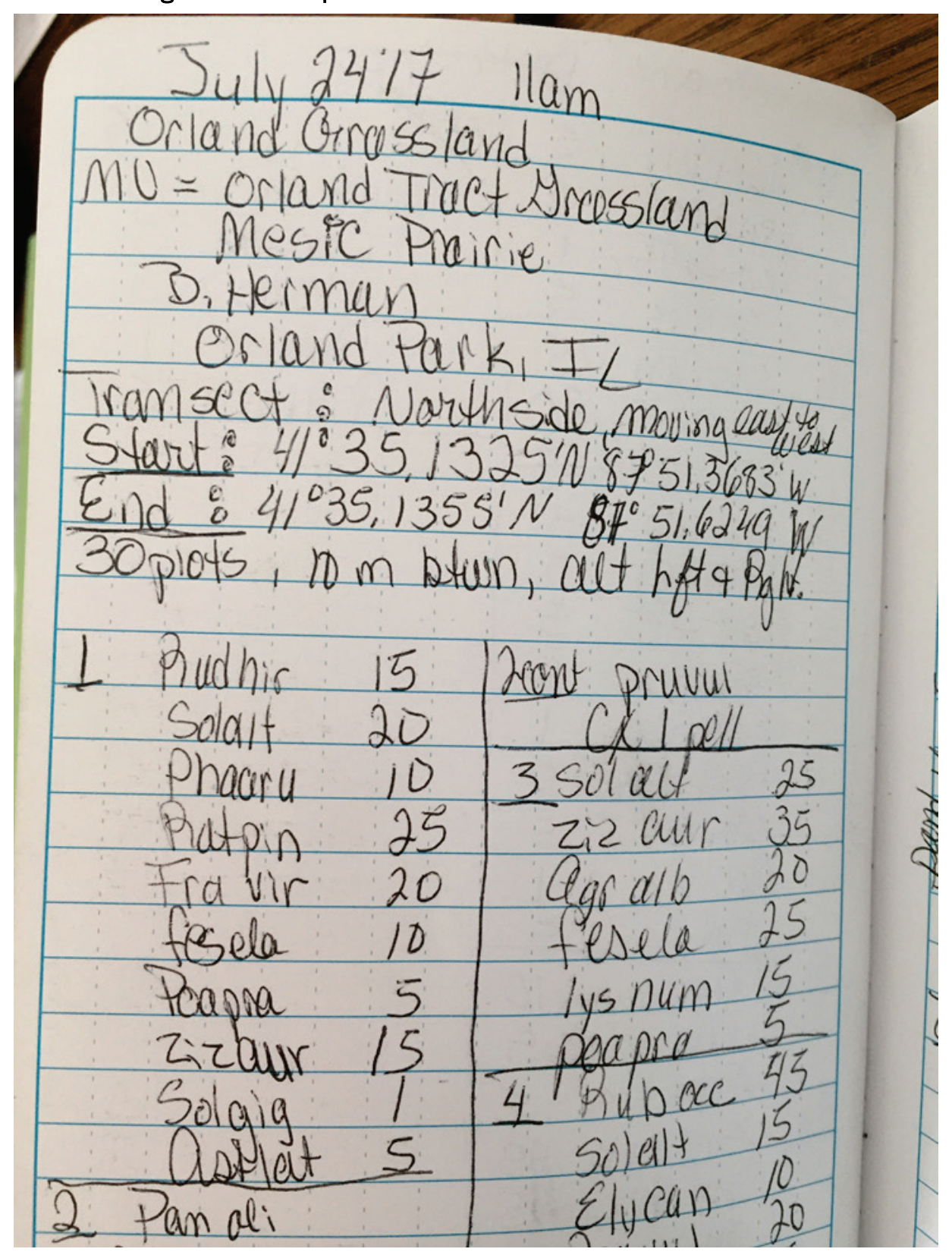

For species that are not readily identifiable in the field, the monitor should assign that species its own unique identifier (e.g., Forb \#1, Carex\#3, etc.) to make sure this unknown species is tracked if it is found in more than one plot. Then take a photo of the plant in the field (Figure 11). Multiple photos may be necessary to document various characteristics of the plant, such as relative width of leaves, shape of flower, relative height, etc. Write down a few descriptive features that may be a clue to the identity of the species in the margins of datasheet or notebook, such as, opposite leaves, winged petiole, red labiate flower, etc. If appropriate, take one or two 
individuals and either preserve the specimens with a plant press or quickly refrigerate in a protective plastic bag. Refrigeration may be not appropriate for some species, generally, small delicate forb species, as they will quickly decompose even in a cool place. Identifying unknown species can be done in a variety of ways and each botanist will have their preferred method. It helps to more fully characterize the management unit if there is time to identify unknown species. It also adds to the skill of the monitor in terms of being able to recognize this species at other sites in the future, this will speed up your rate of data collection.

Figure 11 presents examples of how to photograph unknown plants that emphasize important characteristics, such as seed pods or flower and leaf shape.

Figure 11. Examples of how to photograph unknown plants.
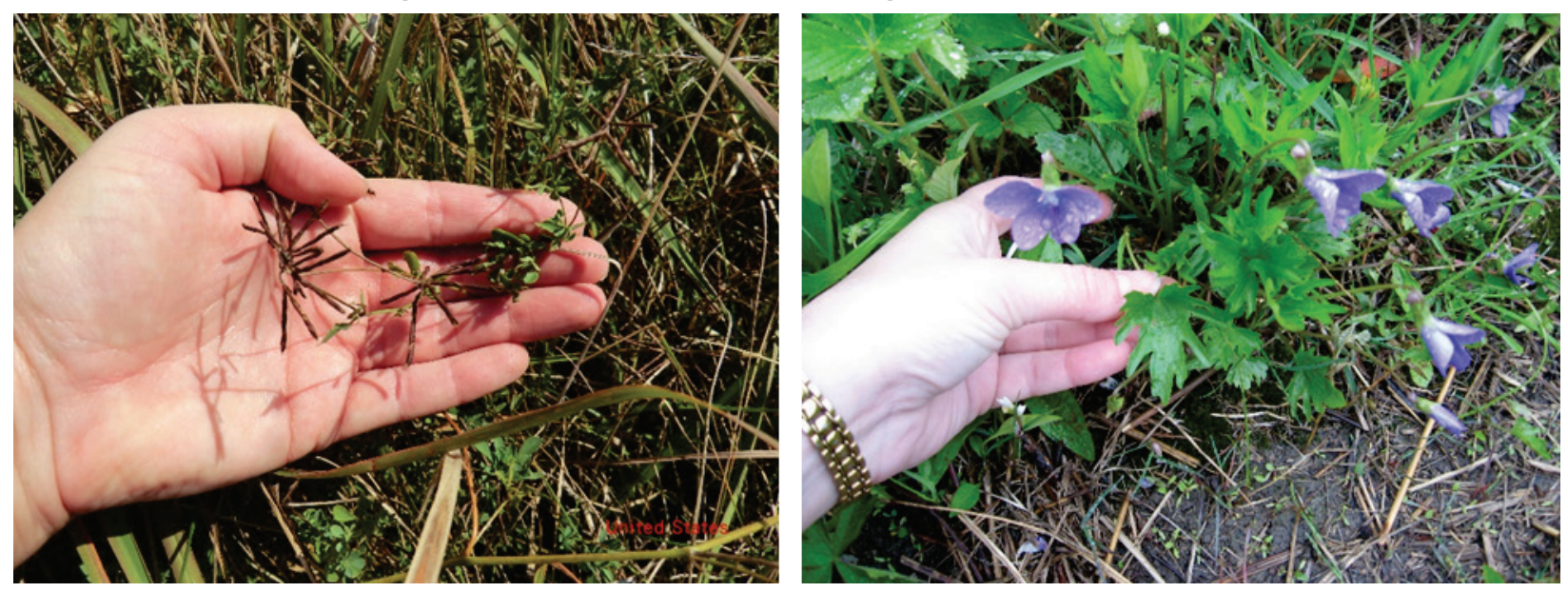

Plot data must be entered into an electronic file (e.g., spreadsheet, access database, etc.) as soon as monitoring has been completed along a transect. There is always a potential for memory loss, especially making sense of short hand notes, if too much time has elapsed between recording and entering data. Be advised that about the same length of time it took to record the data will be needed to enter the data. Electronic files should include all of the descriptive information as the data sheets, such as date, site, management unit, transect, and should be titled in a way that quickly describes the data (e.g., SITE_LOCALE_DATE_Transect\#). Electronic files must be managed in a way that someone not familiar with the site can easily find information for each transect and each year of monitoring. The following is an example of an appropriate file structure:

A. Orland Tract Grassland sect 206 
a. Monitoring

i. 2010

1. Wet Prairie

a. Transects

i. Orland_WetPraire_2010_T2.exl

\subsection{Qualitative sampling}

Recording plant species present within an area of concern in a qualitative fashion can be referred to as a plant species inventory, meander survey, or census. A plant species inventory was a developed to be a repeatable, rapid floristic assessment method (Swink and Wilhelm 1994). One description of this type of qualitative data collection was an exhaustive census of all plant species present (Swink and Wilhelm 1994). Taft et.al. (1997) recommend that multiple site visits are needed to account for potential size of area and temporal changes in species composition (early spring flowering species), and that based on their observations, one site visit during the height of the growing season will record roughly $80 \%$ of species present.

For purposes of this effort, the qualitative sampling protocols will be referred to as a timed meander search, based off of guidance provided by Bohnen and Galatowitsch (2016). The timed meander search is highly recommended to be conducted in parallel with the quantitative method, as described above. However, if needed because of time and budgetary constraints, the timed meander search may serve as a standalone monitoring protocol.

\subsubsection{Selecting management units}

If the timed meander search is conducted in parallel to the quantitative protocols, then the timed meander search would be conducted within each of the management units. If used as a standalone method, then management units would need to be identified and mapped prior to executing the method. Please reference the above sections on how to determine and map management units.

\subsubsection{Meander routes}

The timed meander search must be conducted by determining and mapping walking routes. By mapping walking routes, the method is more 
repeatable between years and between monitors. The number of walking routes will be determined based on the size and complexity of the management unit. A good rule of thumb is at least one-two routes per 30 acres. For example, at least ten walking routes for management units that are 300 acres and greater. Management units that are distributed in discrete patches (Figure 5B) may require a route per patch depending on the level of variability between patches.

Walking routes are similar to walking a transect, they represent areas of the management unit that allows the monitor to visually see and assess as much of the management as possible, and in a way that can be repeatable between years and between monitors. Record walking routes as a dashed line or other type of symbol that shows the difference between a transect that was sampled with plots vs. one that was sampled with a timed meander search. The record (map) will assist the same monitor or another monitor roughly approximate the route that was originally walked. Although a walking route suggests one would walk a straight line through a management unit, in realty, a meander search requires the monitor to seek out plant species and meander around the area for a sufficient amount of time to make accurate identifications. In areas that have permanently placed transects, avoid walking along the exact path of the transect in order to reduce potential trampling along that transect.

\subsubsection{Timed searches}

Baseline length of time that should be spent walking and visually recording plant species is 30 minutes per management unit. If the management unit is of sufficient size or complexity, then additional 20 minute blocks of time may be added. Any additional time must be recorded.

Search time should be paused during periods when time is spent on identifying a difficult species. A rule of thumb in this situation is that if identification requires the use of a field guide and key, the timed search should be paused during that period. Also, pause time when walking between management units or to get to the next walking route in the same management unit if walking routes are widely spaced. 


\subsubsection{Data recorded}

All plant species, herbaceous and woody, encountered within the management unit must be recorded. If the timed meander search is conducted as a standalone method, it is recommended that each species be given a score or indicator that reflects how common or rare the species is within the management unit. Using Figures 8 and 9 as examples of assessing an entire management unit, a monitor will be able to assess whether a species is rare (0.01-5\%), uncommon (5-20\%), common (20$45 \%$ ) or dominant (45-100\%). Although the focus of the standard monitoring protocols is herbaceous vegetation, a management unit may still contain a shrub or tree canopy layer (e.g., oak savanna). If applicable, and would be the type of information needed for management decisions, species may be further designated as belonging to either the herbaceous, shrub, or canopy layer.

In addition to plant species and their indicator of relative abundance, other notes relevant to management decisions should be recorded, such as invasive species. For instance, the relative location and level of dispersal (e.g., one discrete clump vs. multiple singletons evenly dispersed throughout manage unit) across the management unit for each invasive species could be recorded. Often, areas of significant/dominant coverage or newly invading invasive species may be hand drawn or mapped with GPS coordinates in order to enforce certain types of management actions.

\subsubsection{Permanent photo stations}

Permanent photo stations are recommended when conducting the timed meander search as a standalone monitoring method. Photo stations should be mapped and recorded in a way that allows their location to be found for each monitoring event. Mapping of the photo points should include an arrow that indicates the direction the photo was taken. At least one photo station should be assigned per management unit. Photo stations should represent areas that are indicative of the management unit. Photos should also be oriented as to encompass a landscape view and not a small corner of the management unit. When integrating photos into reports, the photos must be accompanied by a description that includes the following information: date photo was taken, name of site, name of management unit, and $1-3$ of the most dominant species at the time the photo was taken. 


\subsubsection{Frequency of timed searches}

Similar to the description given under the quantitative methods, the frequency of the timed meander search method is recommended to be at least once a year during construction and during post-constructions monitoring and adaptive management years. The frequency may be reduced to once every three -five years after the monitoring and adaptive monitoring period.

\subsubsection{Seasonality of timed searches}

Also similar to the description given in the quantitative methods, the optimal timing of the timed meander search is the period of the growing season that the site is accessible and has optimal plant growth and maturity. More than one season may be necessary to sample based on the type plant species (e.g., Carex spp.) present and the goals and objectives of the restoration project.

\subsubsection{Data record and management}

Please see description in the Quantitative Methods section. 


\section{Conclusion}

This report presents the draft standard herbaceous vegetation monitoring protocols developed for the U.S. Army Corps of Engineers (USACE) for use in their Aquatic Ecosystem Restoration projects. The objectives of the protocols are the following: (1) to be able to detect changes in species composition and abundance between years at the same site, (2) to be comparable between sites, (3) to be effective in multiple habitat types, with an herbaceous vegetation layer, and regions of the continental United States, (4) to minimize personal or sampling biases, and (5) to be able to use data for the calculation of appropriate success metrics (e.g., diversity, condition, etc.).

The protocols were developed with a combination of literature review and collaboration with subject matter experts. The protocols will be tested in the field at multiple restoration sites throughout the U.S. Final protocols will be refined or modified based on results of testing and will be made available to the public. 


\section{References}

Albert, C. H., N. G. Yoccoz, T. C. Edwards, Jr, C. H. Graham, N. E. Zimmermann, and W. Thuiller. 2010. Sampling in ecology and evolution - bridging the gap between theory and practice. Ecography 33(6) 1028-1037. doi: 10.1111/j.16000587.2010.06421.x.

Bohnen, J., and S. Galatowitsch. 2016. Restoration evaluation project, vegetation monitoring tool. Minneaplois, MN: University of Minnesota. https://www.lccmr.leg.mn/pm_info/restoration_evaluations/restoration_evaluation_project_ve getation_monitoring_protocol_part_1.pdf.

Bonham, C. D. 2013. Measurements for terrestrial vegetation. $2^{\text {nd }}$ Ed. John West Sussex, UK: Wiley and Sons, Ltd.

Dengler, J., L. Swantje, and C. Dolnik. 2009. Species constancy depends on plot size - a problem for vegetation classification and how it can be solved. Journal of Vegetation Science 20(4):754-766. https://doi.org/10.1111/j.16541103.2009.01073.x.

Elzinga, C. L., D. S. Salzer, and J. W. Willoughby. 1998. Measuring and monitoring plant populations. Denver, CO: Bureau of Land Management, Technical Reference 1730-1.

Gotelli, N. J., and R. K. Colwell. 2011. Estimating species richness. Chapter 4. In Biological Diversity 39-54.

Jensen, M. E., and P. S. Bourgeron. Eds. 2001. A guidebook for integrated ecological assessments. New York, NY: Springer-Verlag.

Kenkel, N. C., and J. Podani. 1991. Plot size and estimation efficiency in plant community studies. Journal of Vegetation Science 2(4):539-544. https://doi.org/10.2307/3236036.

Otýpková, Z., and M. Chytrý. 2006. Effects of plot size on the ordination of vegetation samples. Journal of Vegetation Science 17(4):465-472.

https://doi.org/10.1111/j.1654-1103.2006.tbo2467.x.

Palmer, M. 1990. The estimation of species richness by extrapolation. Ecology 71(3):1195-1198. doi:10.2307/1937387.

Parker, V. T., L. M. Schile, M. C. Vasey, and J. C. Callaway. 2011. Efficiency in assessment and monitoring methods: scaling down gradient-directed transects. Ecosphere. doi: 10.1890/ES11-00151.1.

Stohlgren, T. J., M. B. Falkner, and L. D. Schell. 1995. A modified-whittaker nested vegetation sampling method. Vegetatio 117(2):113-121.

Swink, F., and G. Wilhelm. 1994. Plants of the Chicago Region. $4^{\text {th }}$ edition. Indianapolis, IN: Indiana Academy of Science. 
Taft, J. B., G. S. Wilhlem, D. M. Ladd, and L. A. Masters. 1997. Floristic quality assessment for vegetation in Illinois, a method for assessing vegetation integrity. Erigenia 15:3-23.

U. S. Army Corps of Engineers (USACE). 1987. Corps of Engineers Wetlands Delineation Manual. Y-87-1. Vicksburg, MS: Environmental Laboratory, U.S. Army Engineer Waterways Experiment Station.

U.S. Geological Survey (USGS). 2011. Vegetation standard operating procedures. Unpublished protocols. Vallejo, CA: USGS, Western Ecological Research Center, San Francisco Bay Estuary Field Station.

Vegetation Classification Working Group (VCWG). 2018. https://sites.google.com/site/vegclassmethods/statistical-analyses/datasampling-and-stratification.

Wildi, O. 2013. Data Analysis in Vegetation Ecology. $2^{\text {nd }}$ Ed. West Sussex, UK: John Wiley and Sons, Ltd. 


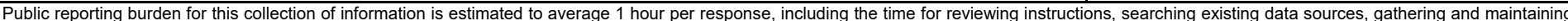

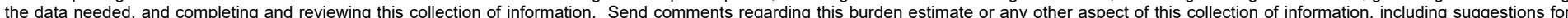

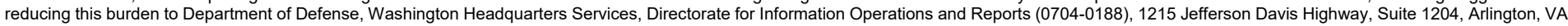

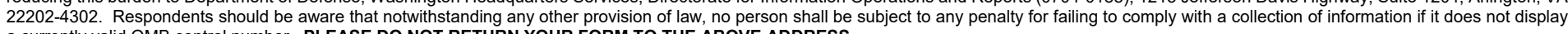
a currently valid OMB control number. PLEASE DO NOT RETURN YOUR FORM TO THE ABOVE ADDRESS.

1. REPORT DATE (DD-MM-YYYY) 1 2. REPORT TYPE June 2019 Final report

3. DATES COVERED (From - To)

4. TITLE AND SUBTITLE

Draft Standard Monitoring Protocols for Herbaceous Vegetation

5a. CONTRACT NUMBER

5b. GRANT NUMBER

5c. PROGRAM ELEMENT NUMBER

6. AUTHOR(S)

Brook D. Herman

5d. PROJECT NUMBER

2015-ER-13

5e. TASK NUMBER

5f. WORK UNIT NUMBER

7. PERFORMING ORGANIZATION NAME(S) AND ADDRESS(ES)

8. PERFORMING ORGANIZATION REPORT NUMBER

U.S. Army Engineer Research and Development Center, Environmental Laboratory 3909 Halls Ferry Road, Vicksburg, MS 39180-6199

ERDC/EL TR-19-4

\section{SPONSORING / MONITORING AGENCY NAME(S) AND ADDRESS(ES)}

10. SPONSOR/MONITOR'S ACRONYM(S)

Headquarters, U.S. Army Corps of Engineers

Washington, DC 20314-1000

11. SPONSOR/MONITOR'S REPORT NUMBER(S)

\section{DISTRIBUTION / AVAILABILITY STATEMENT}

Approved for public release; distribution unlimited.

\section{SUPPLEMENTARY NOTES}

\section{ABSTRACT}

Many methods have been developed over the last century for measuring the characteristics or attributes of plant communities, however, there are no widely accepted standard methods for monitoring vegetation, especially for ecosystem restoration projects. This report presents the draft standard herbaceous vegetation monitoring protocols developed for the U.S. Army Corps of Engineers (USACE) for use in their Aquatic Ecosystem Restoration projects. The objectives of the protocols are the following: (1) to be able to detect changes in species composition and abundance between years at the same site, (2) to be comparable between sites, (3) to be effective in multiple habitat types, with an herbaceous vegetation layer, and regions of the continental United States, (4) to minimize personal or sampling biases, and (5) to be able to use data for the calculation of appropriate success metrics (e.g., diversity, condition, etc.). The protocols will be tested in the field at multiple restoration sites throughout the U.S. Final protocols will be refined or modified based on results of testing and will be made available to the public.

$\begin{array}{lll}\text { 15. SUBJECT TERMS } & \text { Plant ecology } & \text { Ecosystem restoration } \\ & \text { Vegetation monitoring } & \text { Ecosystem management } \\ & \text { Vegetation management } & \text { Restoration ecology }\end{array}$

16. SECURITY CLASSIFICATION OF:

\begin{tabular}{|l|l|l|}
\hline a. REPORT & b. ABSTRACT & c. THIS PAGE \\
UNCLASSIFIED & UNCLASSIFIED & UNCLASSIFIED \\
\hline
\end{tabular}

17. LIMITATION OF ABSTRACT
18. NUMBER OF PAGES

44 19a. NAME OF RESPONSIBLE PERSON

19b. TELEPHONE NUMBER (include area code) 